Review

\title{
Mix design considerations for warm mix recycled asphalt with bitumen emulsion
}

\author{
Marisa Dinis-Almeida ${ }^{\mathrm{a}, *}$, João Castro-Gomes ${ }^{\mathrm{a}, 1}$, Maria de Lurdes Antunes ${ }^{\mathrm{b}, 2}$ \\ ${ }^{a}$ Centre of Materials and Building Technologies, University of Beira Interior, Calçada Fonte do Lameiro, Edifício II das Engenharia, 6200-001 Covilhã, Portugal \\ b Laboratório Nacional de Engenharia Civil, Av. Do Brasil, 101, 1700-066 Lisboa, Portugal
}

\section{A R T I C L E I N F O}

\section{Article history:}

Received 4 May 2011

Received in revised form 4 October 2011

Accepted 4 October 2011

Available online 29 November 2011

\section{Keywords:}

Warm mixtures

Asphalt mixtures design

Pavement recycling

\begin{abstract}
A B S T R A C T
Warm mix recycled asphalt with bitumen emulsion is a technique still in development, which has proved to be very promising, both in economic and environmental terms.

This technology allows recycling at a lower temperature, increases the amount of recycled materials and thus, saves energy and reduces $\mathrm{CO}_{2}$ emissions. It allows to leverage existing raw materials on the degraded pavement and to reduce energy costs in the manufacture of the new mixture. The laboratory study was conducted to analyse the applicability of different design methods to be used with warm mix recycled asphalt, such as Marshall test, immersion compression test, evaluating of water sensitivity and stiffness modulus test. The objective of this paper is to contribute towards defining and developing a design method of such mixtures taking into account the heterogeneity of the recycled asphalt pavement (RAP).
\end{abstract}

(c) 2011 Elsevier Ltd. All rights reserved.

\section{Contents}

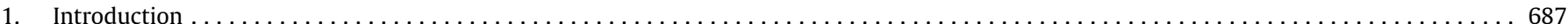

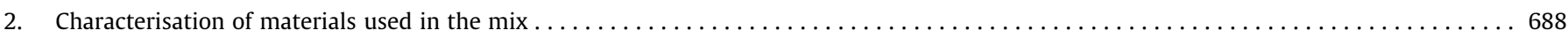

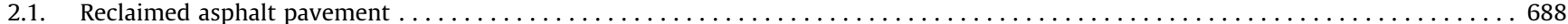

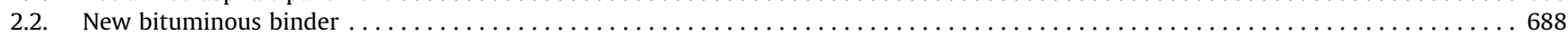

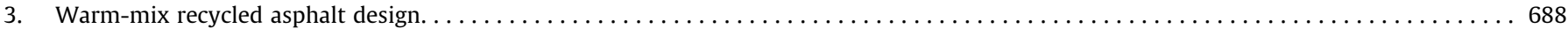

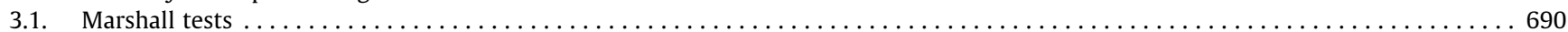

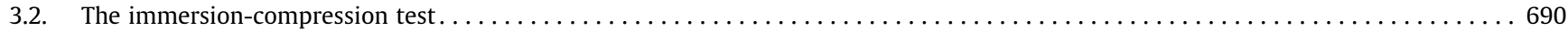

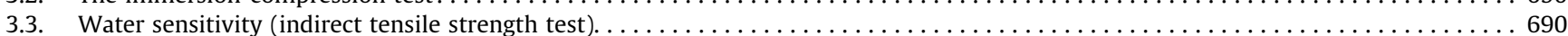

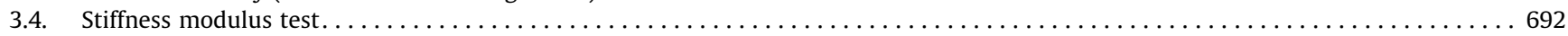

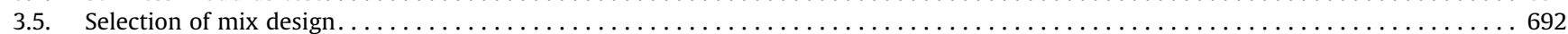

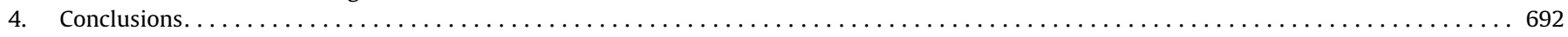

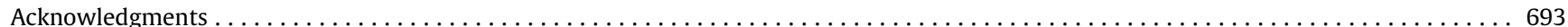

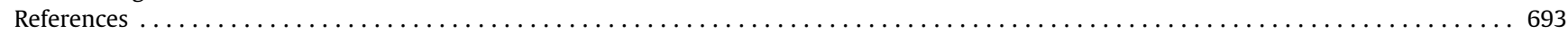

\section{Introduction}

In the construction and rehabilitation of asphalt pavements, large amounts of natural resources are used, in particular, aggregates and binders. These resources are limited and therefore the incorporation and reuse of bituminous aged pavements is important and justified either by environmental issues or by economic

\footnotetext{
* Corresponding author. Tel.: +351 275329706; fax: +351 275329969.

E-mail addresses: marisa.dinis@ubi.pt (M. Dinis-Almeida), castro.gomes@ubi.pt (J. Castro-Gomes), mlantunes@lnec.pt (M. de Lurdes Antunes).

1 Tel.: +351 275329990; fax: +351275329969.

2 Tel.: +351 218443200; fax: +351218443010
}

ones. In Europe, more than 50 million tonnes of asphalt material removed from roads are produced every year [1]. However, in some countries their use in recycled mixtures is still far from desired.

The reasons to recycle materials from the infrastructure of roads can differ from country to country. In countries where almost all the aggregates have to be imported, like the Netherlands, there is an economic basis for optimising the use of reclaimed asphalt pavement (RAP) as far as technically possible. It is verified that about $95 \%$ of mix-plants produce asphalt mixtures incorporating up to 50\% RAP [2]. In countries with sufficient reserves of aggregates, this incentive does not exist. Research conducted over the 
last 30 years shows that the performance of asphalt containing RAP is as adequate as the quality of asphalt containing only natural aggregates [1]. Recycling and the reuse of RAP allows to increase the structural capacity of pavements, their resistance and geometric homogenisation with a minimum use of new materials and removal of landfill deposits.

Currently, there are several types of recycling methods which can be differentiated by the location of production, the type of used binder and the production temperature. As for the location of the recycled mix production, there are two methods: plant-mix and mixed-in-place. Regarding the type of binder used, it can be divided into the bituminous binder and the hydraulic or mixed binder. As for the temperature of production, it has been the cold mix asphalt, the warm-mix or half-warm asphalt and the hot mix asphalt.

Within the different industrial sectors, the production of hot bituminous is an activity that is affected by the Kyoto Protocol. Increasingly industrialised countries seek measures enabling the reduction of emissions in compliance with the requirements. This way, new alternatives of bituminous products or the improvement of the existing are sought, namely, by reducing the temperature of production for conventional bituminous mixtures [3-5]. Thus, the warm-mix recycled asphalt (WMRA) arises and, apart from reducing the emissions, the smoke and the energy necessary for their production, they also improve the safety conditions and comfort during placement. In addition to the advantages mentioned above the WMRA is also applied to resist cold-weather conditions or increasing transport distances before placement. Thus, the smaller differential between ambient temperature and mix temperature results in a slower cooling of the mixture. As a result, WMRA can be compacted at lower temperatures having more time available for the compaction [6-8].

There are three technologies that have been developed and used in European countries to produce WMA $[4,9,10]$ :

1. The addition of a synthetic zeolite called Aspha-Min ${ }^{\circledR}$ during mixing at the plant to create a foaming effect in the binder.

2. A two-component binder system called WAM-Foam ${ }^{\circledR}$ (Warm Asphalt Mix Foam), which introduces a soft binder and hard foamed binder at different stages during plant production.

3. The use of organic additives such as Sasobit ${ }^{\circledR}$, a Fischer-Tropsch paraffin wax and Asphaltan $\mathrm{B}^{\circledR}$, a low molecular weight esterified wax.

These techniques consist in the production of mixtures with additives in order to decrease the viscosity of the binder (bitumen). The technology to produce WMA presented in this paper is based on using of bitumen emulsion as a binder instead of bitumen.

In Portugal, there have been studies on these paving alternatives using $100 \%$ RAP, heated at temperatures between 100 and $140{ }^{\circ} \mathrm{C}$ and adding a small percentage of bitumen emulsion at ambient temperature. Two road works were already done using these mixtures. The first project in Portugal, using warm-mix asphalt recycling with bitumen emulsion was completed in July 2009. This roadwork consists of a $24 \mathrm{~km}$ road rehabilitation, located on EN244 road, between Gavião and Ponte Sor. It is part of a predominantly rural road, with a large amount of agricultural service roads, but with urban areas [11-13]. The aged bituminous pavement was removed to a depth of $7 \mathrm{~cm}$ corresponds to a mixture of different layers of pavement, which included wearing course and part of base course, of the same work performed in 1987. After being removed with a milling machine, the RAP was transported to the hot-mix plant. The laboratory study presented in this paper used the RAP from this roadwork.

The laboratory study was conducted in two stages according to what was proposed by several authors [14-17]. The first stage was to characterise the material composition of warm-mix asphalt recycled (RAP and bitumen emulsion). The second stage determined the approximate amount of asphalt binder through an empirical formula and studied the different design methods in order to choose the most suitable for this type of mixtures.

\section{Characterisation of materials used in the mix}

\subsection{Reclaimed asphalt pavement}

The RAP used in the manufacture of mixtures was from a road rehabilitation work of a pavement, corresponding to a mixture of different layers of pavement, which included wearing course $(6 \mathrm{~cm})$ and part of base course $(1 \mathrm{~cm})$. The bitumen content of RAP was determined by centrifuge extractor method (according to EN12697-1 standard). The results are summarised in Table 1. The analysis of the results presented some variability in the bitumen content of the RAP, varying from 4.1 and 5.3 (percentage by total of aggregates).

The gradation of RAP was determined before the extraction of the binder. RAP was a uniform material and it was consistent with the limit gradation recommended by Portuguese specifications [18]. The results are presented in Table 2.

After the extraction of binder in RAP with the centrifuge extractor method, its characterisation followed. The results obtained are summarised in Table 3.

\subsection{New bituminous binder}

A bitumen emulsion was adopted for the new bituminous binder, manufactured from a bitumen enabled with adequate characteristics to application at temperatures between 100 and $120^{\circ} \mathrm{C}$.

The results regarding the characterisation of bitumen emulsion and the values were described as ideal in the standard EN13808 [19], they are summarised in Table 4.

\section{Warm-mix recycled asphalt design}

The objective of the asphalt mixture design is to study its composition regarding quality and quantity of material to be used so

Table 1

Bitumen content of RAP (\%) determined by centrifuge extractor method.

\begin{tabular}{llllll}
\hline Samples & $C 1$ & $C 2$ & $C 3$ & $C 4$ & Average \\
\hline Bitumen content (\%) & 5.3 & 4.8 & 4.1 & 4.8 & 4.75 \\
\hline
\end{tabular}

Table 2

Grading of RAP.

\begin{tabular}{ccc}
\hline Sieve size $(\mathrm{mm})$ & \multicolumn{2}{c}{ Cumulative $(\%)$} \\
\cline { 2 - 3 } & Passing & Retained \\
\hline 38.10 & 100.0 & 0.0 \\
25.40 & 100.0 & 0.0 \\
19.10 & 100.0 & 0.0 \\
12.70 & 96.8 & 3.2 \\
9.52 & 85.6 & 14.4 \\
4.76 & 67.4 & 32.6 \\
2.36 & 52.0 & 48.0 \\
1.190 & 38.3 & 61.7 \\
0.590 & 27.3 & 72.7 \\
0.297 & 20.0 & 80.0 \\
0.149 & 14.5 & 85.5 \\
0.075 & 9.0 & 91.0 \\
$<0.075$ & 0.0 & 100.0 \\
\hline
\end{tabular}


Table 3

Characterisation of the samples of RAP.

\begin{tabular}{lll}
\hline Characteristics & Sample 1 & Sample 2 \\
\hline Penetration $(\mathrm{dmm})$ & - & 19 \\
Softening point $\left({ }^{\circ} \mathrm{C}\right)$ & 77.8 & 69.6
\end{tabular}

Table 4

Characteristics of the bituminous emulsion

\begin{tabular}{lll}
\hline Properties & Results of tests & EN 13808 \\
\hline Viscosity Saybolt Furol $\left(25^{\circ} \mathrm{C}\right), \mathrm{s}$ & 29 & $20-100^{*}$ \\
Sedimentation after 5 days, \% & 25.4 & $\leqslant 10$ \\
Particle polarity & Positive & Positive \\
Residue on sieving $(0.5 \mathrm{~mm}$ sieve), \% & 0.00 & $170-230$ \\
Breaking value & 210 & \\
Distillation & & $58-62$ \\
Bitumen, \% $(\mathrm{m} / \mathrm{m})$ & 61.5 & $\leqslant 8$ \\
Oil, \% $(\mathrm{v} / \mathrm{m})$ & 0.25 & \\
Distillation residue & & $\leqslant 330$ \\
Penetration at $25{ }^{\circ} \mathrm{C}$ & 103 & $\geqslant 35$ \\
Softening temperature, ${ }^{\circ} \mathrm{C}$ & 46.0 & \\
\hline
\end{tabular}

The viscosity Saybolt Furol does not fit the class requirements of EN 13808. This interval corresponds to the requirements defined in Portuguese specification LNEC E354-1984.

that the mixture has a good behaviour when in service and, under the influence of traffic and atmospheric agents.

Warm mix asphalts (WMA) are within the hot mixtures and the cold mixtures however, there are doubts concerning the design method to be adopted to the WMA. In Portugal, the design method used for hot mixtures is the Marshall test(s) (according to EN12697-34 standard), while, for cold mixtures, it is common to use the immersion-compression tests [20] (according to ASTM D 1075-96 standard). Therefore, we used both tests and checked which would be the most indicated for warm-mix recycling asphalt. In addition, tests to determine water sensitivity (according to EN 12697-12 standard) and characterise the stiffness modulus were carried out (according to EN 12697-26 standard) as an alternative design method.

The approximate amount of bitumen was determined, for all cases, based on the combination of aggregates contained in the RAP and the Eq. (1), proposed by various authors [22]:

$P_{b}=0.035 a+0.045 b+K c+F$

where $P_{b}$ is the approximate total bitumen demand of recycled mixture, percent by weight of mixture, $a$ is the percent of mineral aggregate retained on $2.36 \mathrm{~mm}$ sieve, $b$ is the percent of mineral aggregate passing the $2.36 \mathrm{~mm}$ sieve and retained on the $75 \mu \mathrm{m}$ sieve, $c$ is the percent of mineral aggregate passing on $75 \mu \mathrm{m}$ sieve, $K$ is the 0.15 for $11-15 \%$ passing $75 \mu \mathrm{m}$ sieve, 0.18 for $6-10 \%$ passing $75 \mu \mathrm{m}$ sieve, 0.20 for $5 \%$ or less passing $75 \mu \mathrm{m}$ sieve and $F$ is the $0-2 \%$ absorption factor of aggregates. In the absence of information used by $0.7 \%[21,22]$.

Was applied Eq. (1) using the values presented in Table 2: $a=48 \%, b=43 \%, c=9 \%, k=0.18$ and $F=0.7 \%$. The value obtained for $P_{b}$ was $5.9 \%$. The quantity of new bituminous binder $\left(P_{n b}\right)$ to be added to the recycled mix expressed as percent by weight of aggregate is calculated by the Eq. (2).

$P_{n b}=P_{b}-\frac{(100-r) \cdot P_{s b}}{100}$

where $r$ is the new aggregate expressed as a percent of the total aggregate in the recycled mix, and $P_{s b}$ is the bitumen content of RAP. Table 1 presents the values obtained for the bitumen content of the RAP, with an average value of $4.75 \%$. As the mixture studied is composed of $100 \%$ RAP, the value of $r$ is zero and the value obtained for $P_{n b}$ is $1.15 \%$. The new binder used, as mentioned above, is a bitumen emulsion with $61.5 \%$ of residual bitumen. Thus, the initial content of bitumen emulsion to add to the recycled mixture is $2.0 \%$, approximately.
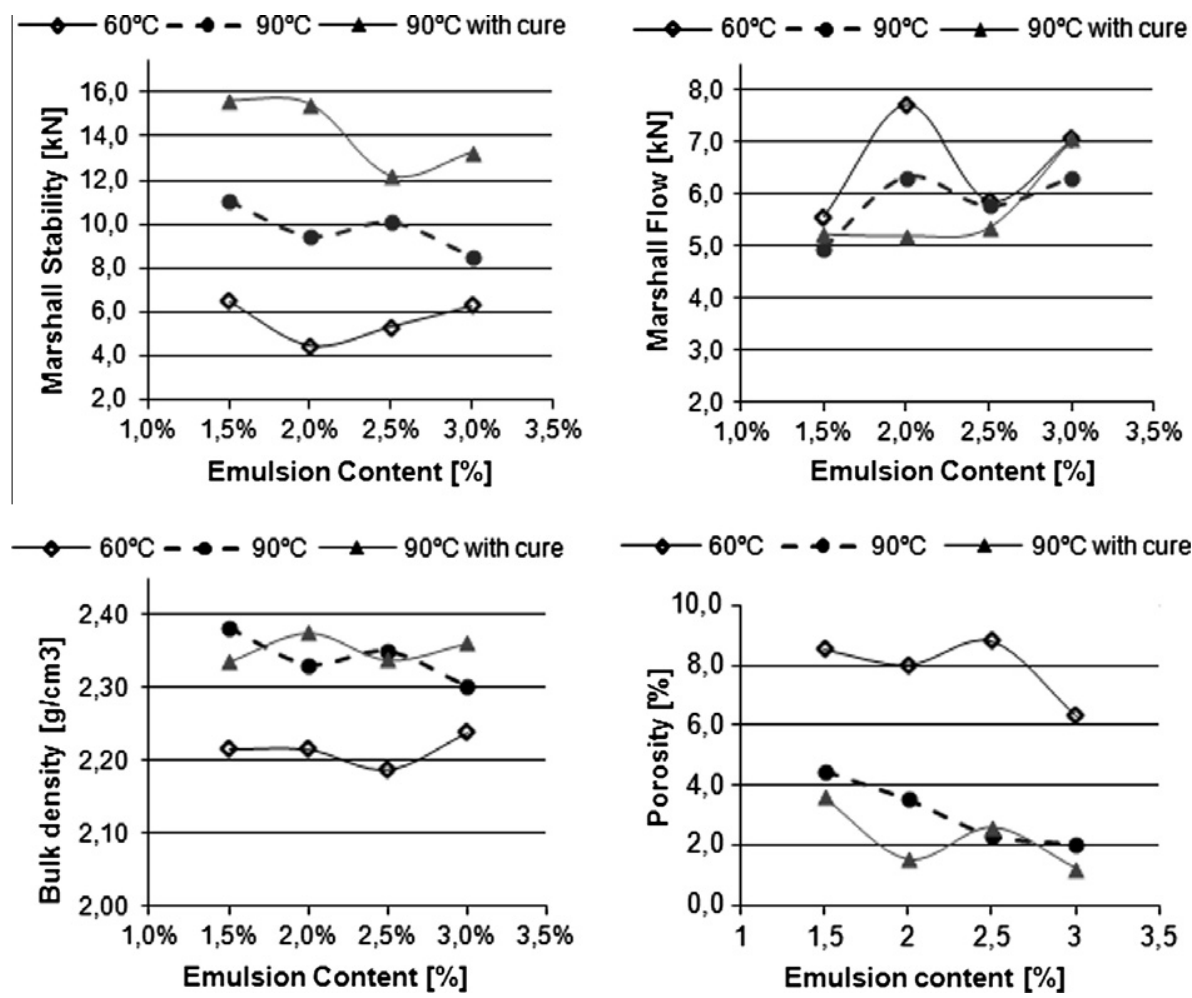

Fig. 1. Graphics resultant from Marshall test. 
Table 5

Requirements for bituminous hot mixtures [13].

\begin{tabular}{ll}
\hline The base courses - requirements/properties & \\
\hline Marshall stability $(\mathrm{kN})$ & $S \min =7.5 ; S \max =15$ \\
Marshall deformation $(\mathrm{mm})$ & $F \min =2 ; F \max =4$ \\
Porosity (\%) & $P \min =3 ; P \max =6$ \\
\hline
\end{tabular}

Next follows a description of the laboratory work carried out in the four separate methods.

\subsection{Marshall tests}

In the laboratory, there was a production and a compaction of recycled mixtures with different contents of emulsion $(1.5 \%, 2.0 \%$, $2.5 \%$ and $3.0 \%$ ), different compacting temperatures $\left(60{ }^{\circ} \mathrm{C}\right.$ and $\left.90{ }^{\circ} \mathrm{C}\right)$ and different types of cure $(24 \mathrm{~h}$ at ambient temperature and $24 \mathrm{~h}$ in an oven at $60^{\circ} \mathrm{C}$ ). For both methods their bulk densities were determined. In Fig. 1 there is a graphic representation of the relationship between some properties resulting from the Marshall test and the emulsion content [13-15]. The results correspond to an average of 5 values for each different mix.

After the analysis of the results obtained for different compacting temperatures and curing, the improvements are noticeable when the temperature and the cure increases, as in the case of mixtures at $90^{\circ} \mathrm{C}$ with $24 \mathrm{~h}$ curing in an oven at $60^{\circ} \mathrm{C}$.

The Marshall test results for estimating the optimum binder content remained inconclusive for all the recycled mixes, when compared to the Portuguese specification limits of the virgin hot mix (Table 5). The optimum binder content corresponds to the maximum Marshall stability, to the highest bulk density and to the average value of the specified porosity limits.

The temperature increases compression to $90{ }^{\circ} \mathrm{C}$ improved the results, however, did not allow clear conclusions about the optimum binder content.
Table 6

Requirements for the characteristics of WMRA (EP, 2009).

\begin{tabular}{ll}
\hline Base courses - requirements/properties & \\
\hline Compressive strength of a dry specimen & $>3 \mathrm{MPa}$ \\
Compressive strength of a immersed specimen & $>2.5 \mathrm{MPa}$ \\
Index of retained strength & $>75 \%$ \\
Porosity (\%) & $4-10 \%$ \\
\hline
\end{tabular}

\subsection{The immersion-compression test}

The immersion-compression test consists on evaluating the effect of water on the cohesion of bituminous mixtures by determining the percentage reduction of simple compressive strength on specimens after immersion in water, at $60^{\circ} \mathrm{C}$ and during a period of $50 \pm 10 \mathrm{~min}$. It was performed as per ASTM D1075 by determining the compressive strength of a dry specimen $\left(S_{D}\right)$, the compressive strength of an immersed specimen $\left(S_{I}\right)$ and the index of retained strength. The obtained results corresponded to an average of 10 values for each different mix are represented in Fig. 2.

After analysing the results and comparing them to the requirements of warm mixture recycled asphalt (Table 6), it can be concluded that, under any conditions, the values of the index of retained strength are within the limits, except for mixtures compacted at $60{ }^{\circ} \mathrm{C}$ with $3 \%$ emulsion content. As to the results obtained for dry resistance and resistance after immersion, all values are higher than the minimum, except for mixtures compacted at $60^{\circ} \mathrm{C}$ with emulsion content equal to $3 \%$.

The mixture design by immersion-compression presented great variability of results. This variability is particularly affected by the lowest compaction temperature.

\subsection{Water sensitivity (indirect tensile strength test)}

The evaluation method of water sensitivity in bituminous mixtures presented in standard EN 12697-12 was based on the comparison between the average values to the indirect tensile
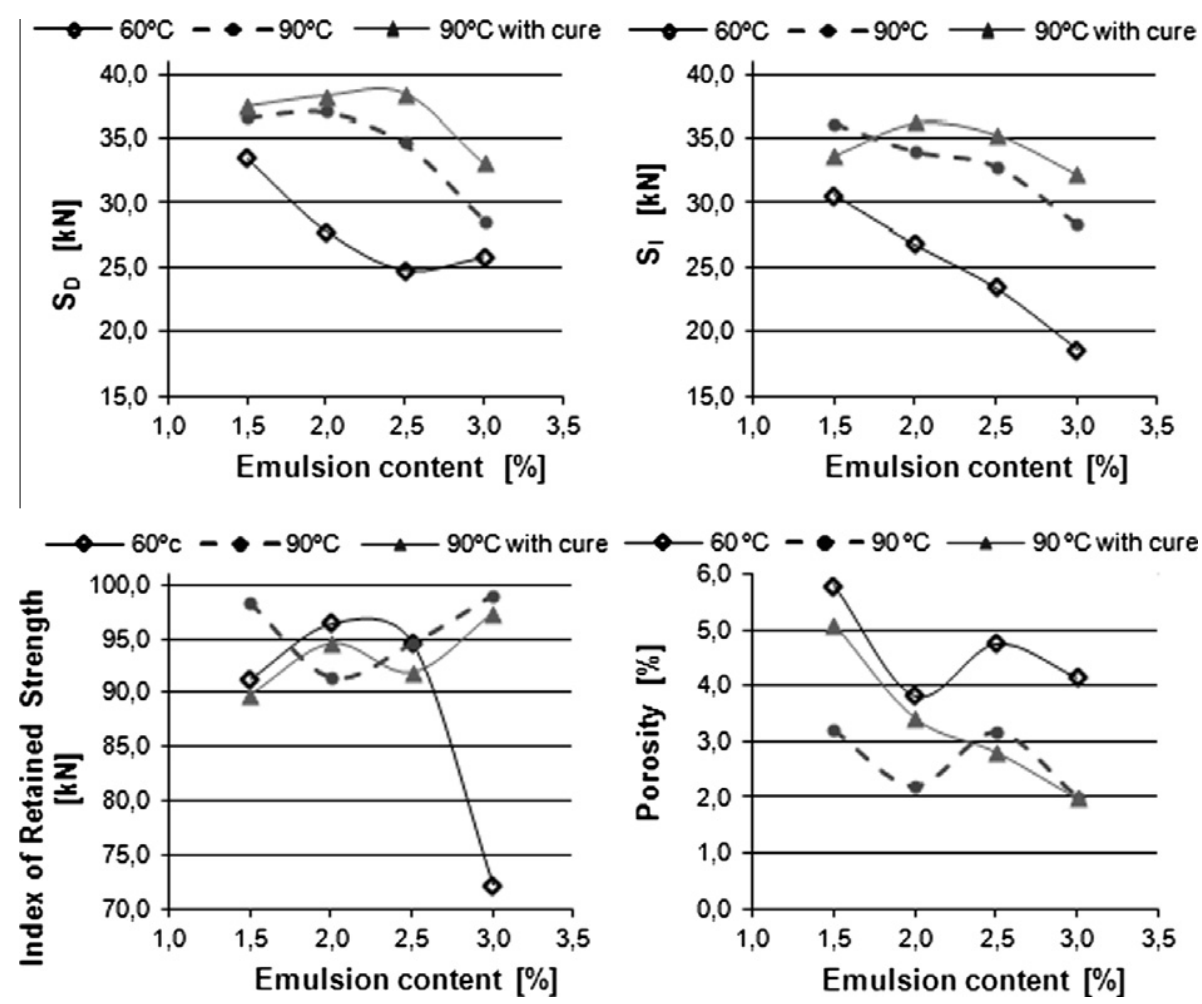

Fig. 2. Graphics resultant from immersion-compression test. 
strength which come from two groups of cylindrical specimens previously kept in different conditions. One group of specimen was kept dry at $20 \pm 5{ }^{\circ} \mathrm{C}$ while a vacuum with distilled water at $20 \pm 5{ }^{\circ} \mathrm{C}$ was applied in order to obtain an absolute pressure of $6.7 \pm 0.3 \mathrm{kPa}$ within $10 \pm 1 \mathrm{~min}$. The specimen was kept in vacuum for $30 \pm 5 \mathrm{~min}$. Next, they were placed in a water bath at $40 \pm 1^{\circ} \mathrm{C}$ for a period of 68 to $72 \mathrm{~h}$. The indirect tensile strength was determined in accordance with the procedure in EN 12697-23, with a load application at a constant speed of deformation of $50 \pm 2 \mathrm{~mm} / \mathrm{min}$. The results obtained are presented in Fig. 3 .

The values for the porosity of WMA are defined, in the Portuguese specifications, between $4 \%$ and $10 \%$. It appears that none of the mixtures meet that limit. The Portuguese specifications do not have limits in the indirect tensile test for the base courses. In Spain, this value for the base courses is $80 \%$. All values obtained were equal to $100 \%$, meeting this limit. This result shows that
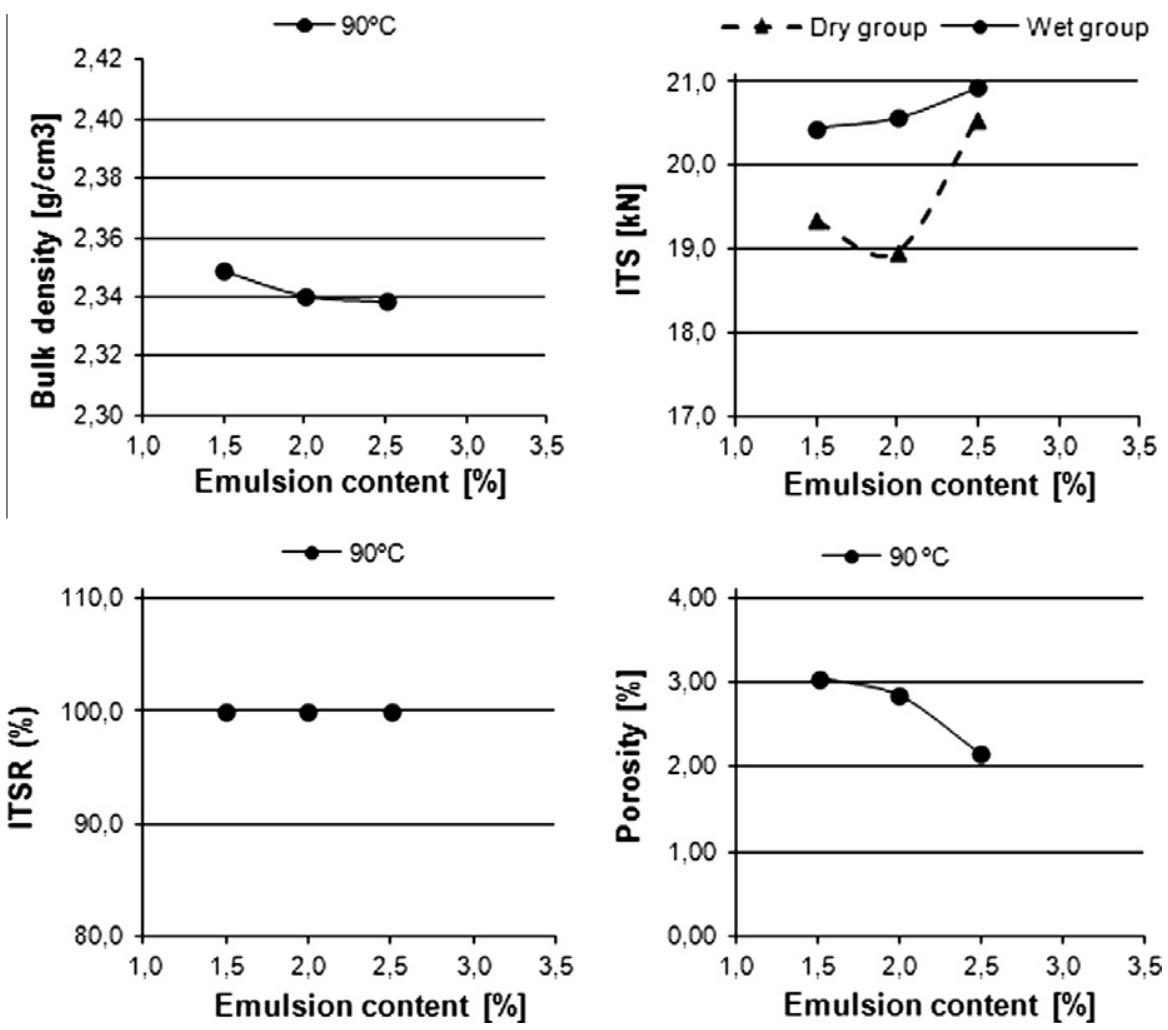

Fig. 3. Graphics resultant from indirect tensile strength test.
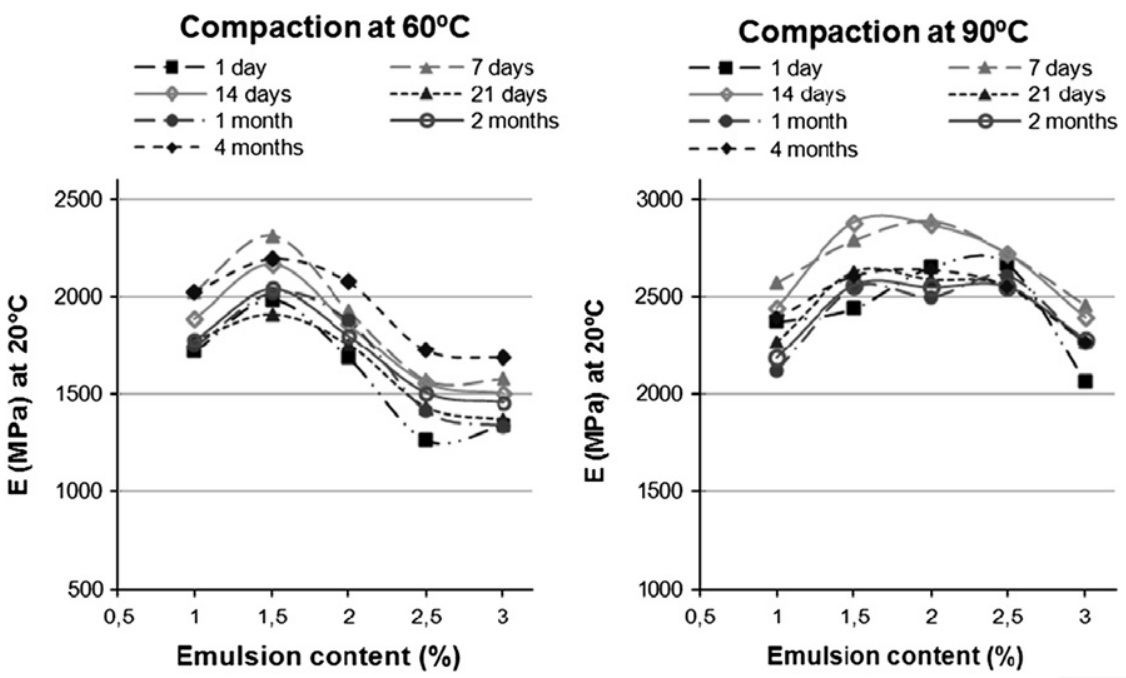

Fig. 4. Variation of the stiffness modulus with emulsion content (specimens compacted at $60{ }^{\circ} \mathrm{C}$ and $90{ }^{\circ} \mathrm{C}$ ). 
Table 7

Mix design study for the WMRA with bitumen emulsion.

\begin{tabular}{|c|c|c|c|c|}
\hline Test conditions & Marshall test & Immersion-compression test & Water sensitivity & Stiffness \\
\hline Specimens dimensions & $\begin{array}{l}\Phi=101.6 \pm 0.1 \mathrm{~mm} \\
h=63.5 \pm 2.5 \mathrm{~mm}\end{array}$ & $\begin{array}{l}\Phi=101.6 \pm 0.1 \mathrm{~mm} \\
h=101.6 \pm 0.1 \mathrm{~mm}\end{array}$ & $\begin{array}{l}\Phi=101.6 \pm 0.1 \mathrm{~mm} \\
h=63,5 \pm 2,5 \mathrm{~mm}\end{array}$ & $\begin{array}{l}\Phi=101.6 \pm 0.1 \mathrm{~mm} \\
h=\text { variable }\end{array}$ \\
\hline $\begin{array}{c}\text { Preparation of } \\
\text { specimens }\end{array}$ & $\begin{array}{l}\text { Compaction Marshall ( } 50 \\
\text { blows } \\
\text { on each side) }\end{array}$ & $\begin{array}{l}\text { Estática de duplo efeito } \\
\begin{array}{l}t=2-3 \mathrm{~min}: \\
p=0 \text { at } 8 \mathrm{MPa} \\
t=2 \mathrm{~min}: p_{\text {cte }}=8 \mathrm{MPa}\end{array}\end{array}$ & $\begin{array}{l}\text { Compaction Marshall } \\
\text { ( } 50 \text { blows on each side) }\end{array}$ & $\begin{array}{l}\text { Static compression of double } \\
\text { effect: } \\
t=2-3 \mathrm{~min} \\
p=0 \text { at } 8 \mathrm{MPa} \\
t=2 \mathrm{~min}: p_{\text {cte }}=8 \mathrm{MPa}\end{array}$ \\
\hline Cure & $\begin{array}{l}4 \mathrm{~h} \text { in mould at room temp. } \\
24 \mathrm{~h} \text { in air at room temp. }\end{array}$ & $\begin{array}{l}2 \mathrm{~h} \text { in mould at room temp. } \\
24 \mathrm{~h} \text { in air at room temp. }\end{array}$ & $\begin{array}{l}16 \text { a } 24 \mathrm{~h} \text { in mould at } \\
\text { room temp. }\end{array}$ & $\begin{array}{l}2 \mathrm{~h} \text { in mould at room temp. } \\
1 \text { day in air, at } 20^{\circ} \mathrm{C}\end{array}$ \\
\hline \multicolumn{5}{|l|}{ Specimens conditioning } \\
\hline Without immersion & - & $\begin{array}{l}24 \mathrm{~h} \text { in oven } 25 \pm 1^{\circ} \mathrm{C} \\
2 \mathrm{~h} \text { in water } 25 \pm 1^{\circ} \mathrm{C}\end{array}$ & $\begin{array}{l}68 \text { a } 72 \mathrm{~h} \text { in air at } 20 \pm 5^{\circ} \mathrm{C} \\
2 \mathrm{~h} \text { in air at } 15^{\circ} \mathrm{C}\end{array}$ & In air at $20^{\circ} \mathrm{C}$ \\
\hline With immersion & $50 \pm 10 \mathrm{~min}$ in water at $60^{\circ} \mathrm{C}$ & $\begin{array}{l}24 \mathrm{~h} \text { in water at } 60 \pm 1^{\circ} \mathrm{C} \\
2 \mathrm{~h} \text { in air at room temperature } \\
2 \mathrm{~h} \text { in water at } 25 \pm 1^{\circ} \mathrm{C}\end{array}$ & $\begin{array}{l}30 \pm 5 \text { min. in vacuum } \\
(66.7 \text { mbar }) \\
68 \text { at } 72 \mathrm{~h} \text { in water at } 40 \pm 1{ }^{\circ} \mathrm{C} \\
2 \mathrm{~h} \text { in water at } 15^{\circ} \mathrm{C}\end{array}$ & - \\
\hline Test & $\begin{array}{l}\text { Compression in stabilometer } \\
\text { "Marshall" ( } v=50.8 \mathrm{~mm} / \mathrm{min})\end{array}$ & $\begin{array}{l}\text { Uniaxial compression } \\
(v=5.08 \mathrm{~mm} / \mathrm{min})\end{array}$ & $\begin{array}{l}\text { Compressão diametral } \\
(v=50.8 \mathrm{~mm} / \mathrm{min})\end{array}$ & $\begin{array}{l}\text { Indirect tensile strength } \\
\text { Repeated load } \\
\text { Controlled strain } \\
\text { Rise time } 124 \mathrm{~ms}\end{array}$ \\
\hline
\end{tabular}

$\Phi$ - Inside diameter of the moulds, $h$ - Height of the moulds, $t$ - Time of loading, $p$ - Compaction pressure.

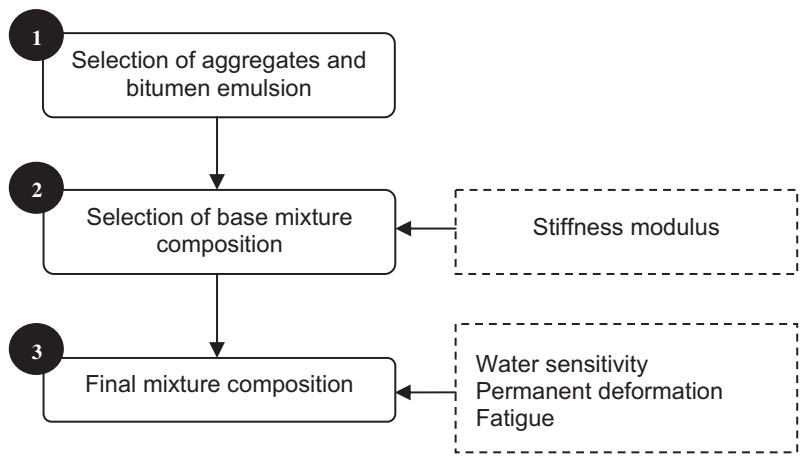

Fig. 5. Mix design proposed for WMRA.

the test is not sensitive to this type of mixture. It can be concluded that this is not appropriate for a design method of the WMRA.

\subsection{Stiffness modulus test}

For the determination of Stiffness (EN12697-26) several specimens were compacted, using static compression of double effect, at $8 \mathrm{MPa}$, as it was found that the apparent density obtained for this compression value would be similar to the one obtained in study [20]. As to the Stiffness test, the results obtained for the mixture performed at $90{ }^{\circ} \mathrm{C}$ were slightly higher than those of mixture performed at $60^{\circ} \mathrm{C}$ (Fig. 4). The results correspond to an average of 5 values for each different mix.

This study was conducted over 4 months, within which the stiffness modulus test was carried out with specimens of different ages: 1 day, 7 days, 14 days, 21 days, 1 month, 2 months and 4 months. During this period the specimens were kept at $20^{\circ} \mathrm{C}$.

With this test the optimum emulsion content for the composition of the mixture can be selected for just a 1 day cure. The specimen compacted to $60^{\circ} \mathrm{C}$ with a higher stiffness modulus were mixtures with $1.5 \%$ of the emulsion content. The specimen compacted at $90{ }^{\circ} \mathrm{C}$ with a higher stiffness modulus were mixtures with $2 \%$ of the emulsion content, being the results close to the specimens with $1.5 \%$ of the emulsion content.

\subsection{Selection of mix design}

The selection of the most appropriate mix design to be applied in WMRA with bitumen emulsion was based on a set of parameters related to the feasibility of tests, obtaining results within a reasonable time, the quality of results and also the simulation of conditions of service as close as possible to reality. Table 7 presents the conditions used within the different methods of mix design, of the referred study.

The test for determining the stiffness modulus proved to be more suitable for use in mix design of WMRA since they obtained results more coherent and with less variability.

To prove the formula for implementing the final mixture, three performance tests were carried out: the water sensitivity (indirect tensile strength test), the wheel tracking test to determine the permanent deformation and the four-point bending test on prismatic shaped specimens (4PB-PR) to determine the resistance to fatigue. After the characterisation of mixtures and the checking of results by comparing them to values established in the Portuguese specifications, the formula for the production of WMRA may be chosen. This study is a result of the mix design for WMRA presented in Fig. 5.

\section{Conclusions}

This paper was developed due to the need of establishing a design method suitable for a warm recycled mix. Several design methods have been tested in order to select the most appropriate for this type of mixtures. Tests conducted were: Marshall test, immersion compression test, water sensitivity test and stiffness modulus test. The latter, following the tendency verified in the last two decades in some European countries, such as England, France and Germany.

In the Marshall test, the obtained results were proved to be inconclusive since it is difficult to set minimum and maximum values in the different graphs. It was verified that the temperature production and compaction of the mixtures influences the final results. The best results were obtained for mixtures compacted at $90^{\circ} \mathrm{C}$. The mixtures compacted at $60^{\circ} \mathrm{C}$, in most cases, were excluded for failing to meet specified requirements.

In the design mix by immersion-compression it seems that the values of compressive strength of a dry specimen $\left(S_{D}\right)$, the com- 
pressive strength of a immersed specimen $\left(S_{I}\right)$ and the index of retained strength are kept above the minimum limits, except for mixtures compacted at $60^{\circ} \mathrm{C}$. There is some variability in the results, such as the Marshall test, showing the difficulty of using these methods in design of MBRT. The lower the temperature of the compaction mixture, the higher the obtained variability of the results.

In the design mix made by the method of sensitivity to water for the studied mixtures (compacted to $90{ }^{\circ} \mathrm{C}$ through the compactor impact), the values of indirect tensile strength ratio (ITSR) are all higher than the specified limits (80\%) and close to $100 \%$. This is due to mixtures are quite dense, containing no water penetration into the specimen, and, are therefore not damaged. It was therefore concluded that this test is not sensitive enough to be used as a method of optimising the composition of the MBRT, and it should be accurate in its applicability to this type of mixtures.

As for the mix design, based on the stiffness, it is clearly possible to choose the optimum emulsion content suitable for the composition of the mixture once the results show little variability. The influence of the curing time on the results was also studied. To accomplish this, they attempted to test specimens after 1 day, 7 days, 14 days, 21 days, 1 month, 2 months and 4 months, having been possible to conclude that the choice made for the 4 month composition is the same as a 1 day of cure.

Thus, after analysing the results obtained from different mix design, there is recommendation to optimise the composition of WMRA based on stiffness test. This method revealed a lower variability of results and allowed to reach conclusions in a short time, with only 1 day to cure the specimens. This work showed that the most appropriate design to determine the optimum emulsion content for WMRA is the stiffness test. However, since in this case lower asphalt emulsion content is employed, which is most likely the reason for that maximum value, the test method cannot be generalised as the main test for design of WMA mixes and further research is needed for different mix compositions.

\section{Acknowledgments}

The authors would like to thank to CEPSA for providing bitumen emulsion for the manufacture of bituminous mixtures in the laboratory and the company Construções JJR \& Filhos, S.A., for all information available and the assignment of RAP.

\section{References}

[1] European asphalt pavement association: arguments to stimulate the government to promote asphalt reuse and recycling - position paper; 21 May 2008.

[2] European asphalt pavement association, 2009: asphalt in figures 2009. <http:// www.eapa.org/usr_img/asphalt/AsphaltinFigures2009.pdf.>.
[3] European asphalt pavement association: the use of warm mix asphalt position paper; June 2009.

[4] FHWA: Warm-mix asphalt: European practice. Federal highway administration, US department of transportation. Publication $\mathrm{N}^{\circ}$ FHWA-PL08-007; February, 2008.

[5] Jenkins K. Mix design considerations for cold and half-warm bituminous mixes with emphasis on foamed bitumen. Doctoral dissertation, Stellenbosch university; 2000.

[6] Jenkins, K, Goot JLA, van de Ven MFC, Molenaar AAA. Half-warm foamed bitumen treatment, a new process. In: Proceedings of the 7th conference on asphalt pavements for southern africa - CAPSÁ99. Victoria Falls, Zimbabwe; 29 August-2 September, 1999.

[7] Jenkins KJ, van de Ven MFC. Guidelines for the mix design and performance prediction of foamed bitumen mixes. In: 20th South African transport conference (SATC) Pretória, South Africa. Sesión 1A:7; 16-20 July, 2001. pp. $1-12$.

[8] van de Ven MFC, Jenkins KJ, Voskuilen JLM, Van Den Beemt R. Development of (half-) warm foamed bitumen mixes: state of the art. Int J pavement Eng 2007;8(2):163-75.

[9] Sanchez-Alonso E, Vega-Zamanillo A, Castro-Fresno D, DelRio-Prat M. Evaluation of compactability and mechanical properties of bituminous mixes with warm additives. Constr Build Mater 2011;25(5):2304-11.

[10] Silva HMRD, Oliveira JRM, Peralta J, Zoorob SE. Optimization of warm mix asphalts using different blends of binders and synthetic paraffin wax contents. Constr Build Mater 2010;24(9):1621-31.

[11] Soto JA, Cardoso AJM, e Vieira L. Reciclagem Semiquente em Central. E.N. 244 Entre Ponte de Sôr e o Entroncamento com a EN118 (Gavião). V Congresso Rodoviário Português “Estrada 2008”, Estoril, Portugal; 12-14 Março 2008 [in Portuguese].

[12] Tavares AP, Vieira L. Reciclagem Semiquente em Central. E.N. 244 - Entre Ponte de Sôr e o Entroncamento com a EN118 (Gavião). Seminário: Pavimentos Rodoviários Verdes, CRP, Lisboa, Portugal; 19 de Outubro 2006 [in Portuguese].

[13] Dinis-Almeida M, Castro-Gomes JP. Antunes ML. Reciclagem a semi-quente em Central-Caso Prático, Engenharia 2009-Inovação e Desenvolvimento. Universidade da Beira Interior, Covilhã, 25-27 Novembro 2009 [in Portuguese].

[14] Dinis de Almeida M, Castro Gomes JP, Antunes ML. Contributo para a formulação de misturas recicladas a semi-quente em central, XV CILA Congresso Ibero-Latino Americano do Asfalto; 22 a 27 de Novembro, 2009 [in Portuguese].

[15] Dinis de Almeida M. Caracterização e formulação de misturas betuminosas recicladas temperadas em central. Tese de Doutoramento, Universidade da Beira Interior, Portugal; 2010. [in Portuguese].

[16] Aravind K, Das A. Pavement design with central plant hot-mix recycled asphalt mixes. Constr Build Mater 2007;21(5):928-36. <(http://www.elsevier.com/ locate/conbuildmat)>.

[17] Widyatmoko I. Mechanistic-empirical mixture design for hot mix asphalt pavement recycling. Constr Build Mater 2008;22(2):77-87. <(http:// www.elsevier.com/locate/conbuildmat)>.

[18] Estradas de Portugal. Caderno de Encargos Tipo Obra, Capítulos 14.03 e 15.03 (Pavimentação). Estradas de Portugal, S.A., Fevereiro de 2009 [in Portuguese[

[19] CEN, 2005. EN 13808 - Bitumen and bituminous binders - framework for specifying cationic bituminous emulsions.

[20] Batista FA. Novas técnicas de reabilitação de Pavimentos. Misturas betuminosas densas a frio. Tese de Doutoramento, Laboratório Nacional de Engenharia Civil e Faculdade de Engenharia da Universidade do Porto, Portugal 2004 [in Portuguese].

[21] Asphalt institute. Mix design method for asphalt concrete. MS-2, sixth ed 1995.

[22] Kandhal P, Mallick R. Pavement recycling guidelines for state and local governments - participant's reference book. Federal highway administration, US, department of transportation. Publication No FHWA-SA-98-042; December, 1997. 